\title{
Predictive Validity toward Job Performance of General and Specific Mental Abilities. A Validity Study across Different Occupational Groups
}

\author{
Jaroslaw Grobelny \\ Correspondence: Jaroslaw Grobelny, Institute of Psychology, Adam Mickiewicz University in Poznan, Poland
}

Received: May 24, 2018

doi:10.11114/bms.v4i3.3297
Accepted: June 20, $2018 \quad$ Online Published: July 4, 2018

URL: https://doi.org/10.11114/bms.v4i3.3297

\begin{abstract}
There are two main views on the role of cognitive abilities in job performance prediction. The first approach is based on meta-analysis and incremental validity analysis research and the main assumption is that general mental ability (GMA) is the best job performance predictor regardless of the occupation. The second approach, referred to as specific validity theory, assumes that job-unique weighting of different specific mental abilities (SMA) is a better predictor of job performance than GMA and occupational context cannot be ignored when job performance is predicted. The validity study of both GMA and SMA as predictors of job performance across different occupational groups $(\mathrm{N}=4033, \mathrm{k}=15)$ was conducted. The results were analyzed by calculating observed validity coefficients and with the use of the incremental validity and the relative importance analysis. The results supports the specific validity theory - SMA proved to be a valid job performance predictor and occupational context moderated GMA validity.
\end{abstract}

Keywords: job performance, general mental ability, specific mental abilities, validity study

\section{Introduction}

Cognitive abilities are one of the most-often discussed predictors of job performance. Despite decades of research, some uncertainty can still be found in the field. This study addresses this issue with a view to examining the relative validity of both general (GMA) and specific mental abilities (SMA) toward job performance in a series of occupational groups.

This paper contributes to the literature dedicated to personnel selection by providing empirical data on the relative validity of GMA and SMA for each of the featured occupational groups. The distinctive feature of this study is that it simultaneously investigates both of these predictors in a systematic way, applying both ratings and quantitative criteria of job performance and the varied statistical method, including the recently widespread and robust relative importance analysis method.

\subsection{Theoretical Perspectives}

As Lang et al. (2010) pointed out, the relative importance of GMA and SMA is a "longstanding question in personnel psychology" (p. 595-596). Two main viewpoints can be found in relevant literature. One of them can be called the mainstream or unitarian perspective, while the other arose from the specific aptitude theory (Stanhope \& Surface, 2014).

\subsubsection{General Cognitive Ability}

The main claim in the former theory is that GMA is the best predictor of job performance and so much evidence has been collected in this field that it can no longer be debatable (Schmidt, 2002). Also, single result for GMA will always be superior job performance predictor over two or more specific factors combined (Schmidt, 2002). Furthermore, the proponents of this perspective argue that the only reason that SMA tests have validity is the loading of the $g$ factor (Carretta \& Ree, 2000) and therefore the predictive validity comes solely from GMA. Finally, no validity in predicting job performance would be gained from SMA and even if it were to be noted, it would be infinitesimal (Olea \& Ree, 1994; Viswesvaran \& Ones, 2002). Statements such as this are mostly based on a variety of meta-analysis studies, which show the validity of GMA tests and studies applying incremental validity analysis based on hierarchical regression models (e.g. Bertua, Anderson, \& Salgado, 2005; Carretta \& Ree, 1997; Hirsh, Northrop, \& Schmidt, 1986; Hunter \& Hunter, 1984; Salgado et al., 2003; Schmidt \& Hunter, 1998). 


\subsubsection{Specific Validity Theory}

The second perspective, variously referred to as the differential aptitude theory, differential validity theory, multiple aptitude theory, and specific validity theory (hereinafter referred to as SVT) (Lang et al., 2010; Richardson \& Norgate, 2015; Stanhope \& Surface, 2014) postulates that "job-unique weighting of several specific aptitudes (...) is greatly superior to intelligence alone in predicting (...) performance" (Ree \& Earles, 1992, p. 87). Broadly speaking, the assumption here is that if prediction is supposed to be valid, it should be made for a specific context (e.g. a chosen occupation) and based on specifically chosen predictors (which fit that context). These theories are considered by some to have been disproved (see Schmidt, 2002), while others believe that the dispute about the impact of GMA and SMA on performance has not been resolved. There are authors who have claimed that a composite combined out of SMA, i.e. narrow cognitive abilities (or a job-specifically weighted composite) would be superior in terms of job performance prediction to GMA (see Krumm, Schmidt-Atzert, \& Lipnevich, 2014; La Grange \& Roodt, 2007; Lang et al., 2010; Stanhope \& Surface, 2014).

\subsection{Review}

The mainstream view of the superior role of GMA in job performance prediction puts forth three major claims. These are: 1) GMA is the single most valid predictor of job performance 2) GMA is valid regardless of the occupational context 3) no incremental validity should be expected from SMA (Schmidt, 2002). It is reasonable to present and discuss the matter thoroughly in order to justify interest in this topic, as there are a number of doubts regarding each of the above statements.

\subsubsection{Concerns about the Superior Role of GMA in Job Performance Prediction}

The claim of the best predictive validity magnitude of GMA comes primarily from meta-analytic studies. These studies summarized the results of the validity of different tests from hundreds of samples. Overall, they have shown validity coefficients c.a. $0.3-0.5$ (Bertua et al., 2005; Schmidt \& Hunter, 1998). In most meta-analyses, one major coefficient (or a few, at most) is reported, and it summarizes studies conducted in a variety of conditions and in many, sometimes vastly different, contexts. As a consequence, an important amount of information may be lost because of such generalization. Moreover, there is considerable uncertainty regarding the actual impact of meta-analytic correction procedures on the estimated outcomes (Lakens, Hilgard, \& Staaks, 2016; LeBreton, Scherer, \& James, 2014; Richardson \& Norgate, 2015).

Given the important uncertainty presented above, if one decides to investigate the primary studies related to the topic, some puzzling results could also be found. First, there is a major part of studies that presents no validity of GMA at all in predicting job performance variance. Hirsh et al. (1986) reported no validity of GMA for law enforcement occupations. Hogan, Hogan \& Gregory (1992) found no relationship between GMA and measures of job performance for salespeople. In addition, Verbeke et al. (2008) provided an extensive list of studies in which GMA were not related to the performance of sales staff. There were no connections, either, between GMA tests scores and quantitative measures in such occupations as recruitment consultants, bankers, insurance representative, and transit operators (Barros, Kausel, Cuadra, \& Díaz, 2014; Downey, Lee, \& Stough, 2011; Hausdorf \& Risavy, 2015; La Grange \& Roodt, 2007). Secondly, numerous examples of SMA that proved to be a valid job performance predictor (more than GMA) in certain context can be found as well; these are: mechanical comprehension and mechanical reasoning for manufacturing employees (Muchinsky, 1993), performance correctness (Thomas, Barrett, \& Alexander, 1996) and performance speed for clerks (Whetzel et al., 2011) or perceptual speed for warehouse workers (Mount, Oh, \& Burns, 2008). Schmidt (2002) cited examples of nine validation studies where the comparison between GMA and SMA could be made in nine occupations. In six cases, SMA had a superior predictive magnitude over GMA. Marcus, Johnston \& Rothstein (2007) investigated managers in the forestry sector and found that composites based on several SMA had a superior predictive validity over GMA. Finally, as Krumm et al. (2014) mentioned, more recent evidence from meta-analytic studies shows that SMA could be not only an additional, but even a more important predictor of performance than GMA.

The above study results contradict the mainstream viewpoints of the principal role of GMA in job performance prediction. This may, at first glance, seem a "cherry picking" practice, as primary study results are always more prone to error than meta-analytic reviews. It is however far from the truth, as thorough analysis lists a series of factors that may moderate the relation between both GMA and SMA with job performance. Firstly, when SMA results are computed in alignment with a given criterion and estimated specifically for the occupation group examined, it could account for a great deal of variance in job performance (Ree \& Earles, 1992; Reeve, 2004; Schneider \& Newman, 2015). Next, GMA appears to lose validity towards job performance while other characteristics, e.g. social skills, are being considered simultaneously (Cote \& Miners, 2006; Schneider \& Newman, 2015). Furthermore, while more robust measures of job performance than supervisory ratings are used, GMA appeared to be a weak or an insignificant predictor (La Grange \& 
Roodt, 2007; Vinchur, Schippmann, Switzer, \& Roth, 1998). Finally, the occupational context itself seems to be a major moderator of the validity magnitude for the predictors discussed.

\subsubsection{Concerns about the Universal Validity of GMA in Performance Prediction in a Variety of Occupations}

As stated above, the validity of both GMA and SMA seems to vary greatly between different occupations. Ree and colleagues (Olea \& Ree, 1994; Ree, Earles, \& Teachout, 1994) found predictive validity rates of GMA from 0.26 for air traffic operators and up to 0.71 for laboratory specialists or mechanics. In the study of Bertua et al. (2005), the coefficients range was also broad, from 0.14 and 0.16 for clerks and drivers, up to 0.33 for engineers. Similarly, in Salgado et al. (2003), they were from $0.12-0.20$ for police and drivers, up to $0.31-0.34$ for clerks and sales staff. It appears that the magnitude of the criterion-related validity of GMA for different occupational groups varied from moderately weak to exceptionally strong. Unfortunately, this differentiation is often omitted in meta-analytic reports, as authors often emphasize few general coefficients estimation and neglect to reports the contextual information or detailed and systematical subgroups comparison. For that reason, sometimes these actual differences in predictive validity of GMA become indistinguishable.

\subsubsection{Concerns about the Lack of Incremental Validity from SMA}

Incremental validity of SMA in job performance prediction, based on Ree and colleagues' work (Carretta \& Ree, 2000; Olea \& Ree, 1994; Ree \& Earles, 1992; Ree et al., 1994), is considered to be almost insignificant. Once again, this might be due to the context considered; as Schneider \& Newman (2015) noticed, this is the case only when all occupations that occurred in a sample (e.g. over 80 ) are considered together.

There may be however methodological reasons to question the evidence regarding the lack of value of SMA (Reeve, 2004). There is an issue with the incremental validity analysis method itself, which is a major method used in primary validation studies (Stanhope \& Surface, 2014). By using hierarchical regression, one can compare two models - one with only an initial predictor (GMA in this case) and a second one with an initial and an additional predictor (e.g. SMA). If there is an increase in the coefficient of determination between the models, one could state that the additional predictor has incremental validity. The issue is that, when predictors are included in the regression, in this approach the shared variance between initial and additional predictors and dependent variables is accounted for in the initial predictor only (Lang et al., 2010; Stanhope \& Surface, 2014).

According to Lang et al. (2010), "as shared variance between GMA (...) and the narrower cognitive ability measures belongs to either GMA or narrower cognitive ability constructs (...), incremental validity analysis does not correspond to the model's assumptions" (p. 604). This statement is based on nested factor models (NFM) of intelligence, which claim that variance in ability tests is explained by both GMA and SMA, contrary to theories originating in the Spearmanian tradition, with its assumption of the causal effect from GMA to SMA. As NFT seems to be more accepted and supported by data (see Lang et al., 2010; Richardson \& Norgate, 2015; Verbeke et al., 2008), there is an issue with the acceptance of results based on incremental validity analysis with GMA as an initial predictor; caution should be recommended at least.

The fact is that the predictive validity of SMA may be considered at the same time to be insignificant, little or highly significant (based on the same dataset), while the only moderator will be the statistical method used (Lang et al., 2010; Reeve, 2004). Researchers consequently need a statistical technique capable of determining the explained variance belonging to each ability construct even when the measures of the constructs are considerably correlated. A technique of this kind is relative importance analysis (RIA). As Johnson and LeBreton (2004) described, it allows one to estimate "the proportionate contribution each predictor makes to $R^{2}$, considering both its direct effect (e.g. its correlation with the criterion) and its effect, when combined with the other variables in the regression equation" (p. 240). This method seems to be much more useful in determining the predictive validity magnitude of SMA and GMA in validation studies and it seems reasonable to at least employ both hierarchical regression models and RIA to compare their results in determining the relative validity of GMA and SMA, as substantial doubts surrounding this matter could be identified.

\subsection{Hypothesis Development}

The empirical reasons for the consideration of the relative validity of GMA and SMA are sufficient. However, there are also strong theoretical grounds to undermine the claims of the superior role of GMA in job performance prediction. A well-established theory of individual differences in job performance by Motowidlo, Borman and Schmidt (1997) will serve as a general framework. Based on this theory, one could expect both a relatively better validity of SMA than GMA and a significant differentiation of abilities validity in different organizational contexts.

The key assumption in this theory is that the variance in job performance is caused by a variability in characteristic adaptations, which are the specific skills and patterns of employees' behaviors. Characteristic adaptations are, in turn, the results of interactions between the basic tendencies (individual differences in personality and abilities) and learning 
experience derived from the environment. Basically, characteristic adaptations are implementation of behaviors required in one's job in a faultless and easy manner. Execution of some specific behavior or task is, in fact, enhanced by a certain, narrow ability (Sternberg, 2001). As tasks and behaviors required in a given occupation tend to be similar (within a certain group), they should be enhanced by a sole SMA (or few at best). Concurrently, as GMA overly enhance general problem solving and functioning, they should be responsible for a variety of behaviors, including those insignificant within a given occupational context. Therefore, their validity would be on average important, however less substantial than the one of SMA. Subsequently, actions required in a given occupation differed greatly (between groups) and therefore a characteristic adaptation needed to perform well should vary too. This led to the logical assumption that basic tendencies required in a given occupation must be different. As a result, the predictive validity of the test of these abilities would vary for different occupational groups. This theoretical explanation, together with empirical evidence discussed above, led to the following two hypothesis:

H1. A validity of SMA toward job performance within a given occupational group is relatively better than GMA.

H2. An occupational group moderates the validity of GMA toward job performance.

\section{Method}

\subsection{Participants' Characteristics}

The participants of this study were Polish candidates $(\mathrm{N}=4033)$ for positions from fifteen different occupational groups (board of directors, buyers, clerks, constructors, consultants, customer service, financiers, HR, IT specialists, manufactory workers, marketing specialists, QA's, researchers, salespeople, and transition specialists). The study included 2,237 (55.47\%) women and 1,796 (44.53\%) men. As many as 1,446 (35.85\%) were in managerial positions. Participants' average age was $31(S D=6.57)$ and they were mostly moderately experienced $(M=7.55 ; S D=6.47)$. The high dispersion suggests that a broad scope of experience levels was represented in the sample. Participants were assigned to occupational groups based on their most recent job position.

\subsection{Measurements}

During the study, the job performance was measured by two measures (both rating and quantitative), while cognitive abilities were measured by a series of on-line cognitive tests. Besides, control variables such as age, overall professional experience and occupational experience (within a given occupational group) were measured.

\subsubsection{Job Performance (Quantitative)}

The first variable that operationalized a job performance was the financial outcomes of participants. The mean salary from the preceding three months was reported by the participants. The assumption here is that better-performing employees are paid better and they are employed by the best-paying companies or at higher positions. The salary is moreover often strongly dependent on the work outcome, as the pay for performance system is a common practice, in particular in certain occupations. To avoid the impact of such confounding factors as wage disparities between occupations, the data were scaled within the analyzed groups before the computations. As the salary is considered to be sensitive information, it was optional for participants to provide this information (to avoid measurement unreliability resulting from false data), yet only cases with no missing data were included into study.

\subsubsection{Job Performance (Rating)}

The second criterion of job performance was self-reported ratings of the average level of job goals completed (e.g. KPI or sales targets). The participants were asked to rate to what degree they realize their professional goals, either formal (e.g. included in management-by-objective system) or informal (e.g. set by a supervisor and communicated in an informal manner). The rating was performed with the aid of a 6-point scale, where 1 means achieving less than $60 \%$ of the goals and 6 means the accomplishment of over $100 \%$.

\subsubsection{Ability Tests}

To measure cognitive abilities, an online test dedicated for personnel selection was used. The test was developed in accordance with strict psychometrical procedures (and validated on a group of 5,572 participants). As a result, the tool met the required standards for psychological tests: it was reliable, as the minimum test-retest coefficients for a 1-month period was 0.89 for each subtest and valid, e.g. selected scales correlated highly with expected scales from WAIS-R and CFT-3 and the factor analysis confirms an expected, hierarchical structure of the results. The tests were developed on the basis of the CHC theory (see Schneider \& Newman, 2015) and therefore each test was designed to measure a chosen narrow ability. Each test consisted of 20 tasks and was time-limited. There were seven tests:

Quantitative reasoning. The ability to perform tasks based on calculation and mathematical operations.

Visualization. The ability to perform tasks that require spatial imagination as well as being able to find and predict 
analogies in given systems of spatial elements.

Reading comprehension. The ability to interpret information and drawing proper conclusions based on various read information.

Deductive reasoning. The ability to apply patterns of logical reasoning as well as drawing proper conclusions based on incomplete information and predefined rules for reasoning.

Lexical knowledge. Verbal ability consisting of a broad vocabulary and an ability to connect elements into basic relations on the basis of knowledge of their meaning.

Inductive reasoning. The ability to recognize relationships between given constructs and predict fitting elements based on rules that need to be identified.

Word fluency. The ability to quickly generate words based on a given criterion.

On the basis of the results of these tests, two further variables were computed.

\subsubsection{GMA}

With the help of the Ordinary Least Squares (OLS) method of factor analysis (to find the minimum residual solution), a single general factor was calculated and extracted. This variable corresponds to the general factor from stratum III in CHC theory and operationalized GMA as well. As different methods of estimating $g$ tend to show a high stability (see Ree \& Earles, 1991), no further general factors were calculated.

\subsubsection{SMA}

This composite was calculated according to the SVT, which means that each narrow ability test result was weighted (based on the validity coefficient for job performance criterion) specifically for a chosen occupational group (Reeve, 2004; Stanhope \& Surface, 2014). These composite scores reflect the specifically weighted choice of SMA, which are valid only for a certain occupation and which have been designed for a given group.

\subsection{Research Procedure}

The data for this study were gathered during actual recruitment processes conducted by a staffing agency. The candidates were able to identify job positions in online job boarding services and then fill out applications on a dedicated platform. Each of the candidates who replied to job ads could create an account with their demographic data, where the criterion measures and abilities tests were conducted. The procedure was administered online and the candidates completed tests in their own time and place; however, they were informed that their scores will be verified by the agency during further stages of the recruitment procedure (this regards both criterion measures and ability tests results). The participants were provided with detailed information about the procedures and tests, so they could make their own decisions whether they would participate in the study and pass the data to the researcher.

\section{Results}

The results of the measures along with a correlation table are shown in Table 1 . The validity of every measured predictor towards both job performance criteria is presented in Table 2. Based on these results, three further analyses were performed: hierarchical regression models, moderation analysis and relative importance analysis.

\subsection{Observed Validity}

First of all, all predictors appeared to have a comparable correlation in the case of both job performance criteria and similar patterns of relationship presented. The observed validity coefficient for the whole sample shows that GMA has moderate validity. Several SMA tests, e.g. quantitative reasoning, reading comprehension and verbal potential, proved to be comparable or slightly weaker predictors, while the rest had in general an unsatisfactory correlation with both job performance criteria. However, the results differ substantially when occupational validity coefficients were analyzed. In one group - of consultants - both SMA and GMA had no validity at all. In the case of clerks, financiers and QA's, GMA had no validity toward both job performance criteria. There were seven groups in which GMA had the strongest correlation with both job performance criteria measured among all single predictors considered.

However, when occupational groups were analyzed, it appeared that there was no single group where GMA would be a significant and a more valid predictor that the SMA composite. Furthermore, there were seven groups in which a single narrow ability test could be identified as the most valid predictor. These data are in favor of both hypotheses, as SMA proved to correlate stronger with job performance measures than GMA did, and the GMA validity differed between groups. 
Table 1. Summary of study results

\begin{tabular}{|c|c|c|c|c|c|c|c|c|c|c|c|c|c|c|c|}
\hline & mean & $\mathrm{sd}$ & 1 & 2 & 3 & 4 & 5 & 6 & 7 & 8 & 9 & 10 & 11 & 12 & 13 \\
\hline 1. age & 30.93 & 6.57 & & & & & & & & & & & & & \\
\hline 2. experience (overall) & 7.55 & 6.47 & 0.91 & & & & & & & & & & & & \\
\hline 3. experience (occupational) & 5.18 & 5.29 & 0.72 & 0.76 & & & & & & & & & & & \\
\hline $\begin{array}{l}\text { 4. job performance (financial } \\
\text { outcome) }\end{array}$ & 4236 & $\begin{array}{l}2 \\
671\end{array}$ & 0.38 & 0.39 & 0.35 & & & & & & & & & & \\
\hline 5. job performance (self-rating) & 3.78 & 0.88 & 0.13 & 0.14 & 0.12 & $\begin{array}{l}0.4 \\
0\end{array}$ & & & & & & & & & \\
\hline 6. QR & 16.80 & 3.79 & 0.02 & 0.04 & 0.04 & $\begin{array}{l}0.3 \\
1\end{array}$ & $\begin{array}{l}0.3 \\
1\end{array}$ & & & & & & & & \\
\hline 7. $\mathrm{V}$ & 16.86 & 3.00 & $\begin{array}{l}-0.0 \\
3\end{array}$ & $\begin{array}{l}-0.0 \\
3\end{array}$ & $\begin{array}{l}-0.0 \\
4\end{array}$ & $\begin{array}{l}0.1 \\
7\end{array}$ & $\begin{array}{l}0.2 \\
1\end{array}$ & $\begin{array}{l}0.3 \\
7\end{array}$ & & & & & & & \\
\hline 8. RC & 15.47 & 3.08 & $\begin{array}{l}-0.0 \\
3\end{array}$ & $\begin{array}{l}-0.0 \\
3\end{array}$ & $\begin{array}{l}-0.0 \\
2\end{array}$ & $\begin{array}{l}0.2 \\
5\end{array}$ & $\begin{array}{l}0.2 \\
7\end{array}$ & $\begin{array}{l}0.5 \\
2\end{array}$ & $\begin{array}{l}0.3 \\
6\end{array}$ & & & & & & \\
\hline 9. DR & 14.58 & 3.74 & $\begin{array}{l}-0.0 \\
3\end{array}$ & $\begin{array}{l}-0.0 \\
6\end{array}$ & $\begin{array}{l}-0.0 \\
2\end{array}$ & $\begin{array}{l}0.1 \\
8\end{array}$ & $\begin{array}{l}0.2 \\
3\end{array}$ & $\begin{array}{l}0.2 \\
9\end{array}$ & $\begin{array}{l}0.2 \\
2\end{array}$ & $\begin{array}{l}0.3 \\
0\end{array}$ & & & & & \\
\hline 10. LK & 17.25 & 2.69 & 0.09 & 0.09 & 0.06 & $\begin{array}{l}0.2 \\
0\end{array}$ & $\begin{array}{l}0.2 \\
2\end{array}$ & $\begin{array}{l}0.2 \\
4\end{array}$ & $\begin{array}{l}0.1 \\
8\end{array}$ & $\begin{array}{l}0.2 \\
5\end{array}$ & $\begin{array}{l}0.2 \\
0\end{array}$ & & & & \\
\hline 11. IR & 19.79 & 2.26 & $\begin{array}{l}-0.0 \\
9\end{array}$ & $\begin{array}{l}-0.0 \\
9\end{array}$ & $\begin{array}{l}-0.0 \\
9\end{array}$ & $\begin{array}{l}0.1 \\
0\end{array}$ & $\begin{array}{l}0.1 \\
9\end{array}$ & $\begin{array}{l}0.3 \\
3\end{array}$ & $\begin{array}{l}0.2 \\
6\end{array}$ & $\begin{array}{l}0.3 \\
4\end{array}$ & $\begin{array}{l}0.2 \\
5\end{array}$ & $\begin{array}{l}0.2 \\
7\end{array}$ & & & \\
\hline 12. WF & 23.43 & 5.20 & $\begin{array}{l}-0.1 \\
2\end{array}$ & $\begin{array}{l}-0.1 \\
3\end{array}$ & $\begin{array}{l}-0.1 \\
1\end{array}$ & $\begin{array}{l}0.0 \\
1\end{array}$ & $\begin{array}{l}0.1 \\
2\end{array}$ & $\begin{array}{l}0.2 \\
4\end{array}$ & $\begin{array}{l}0.2 \\
2\end{array}$ & $\begin{array}{l}0.2 \\
4\end{array}$ & $\begin{array}{l}0.1 \\
9\end{array}$ & $\begin{array}{l}0.1 \\
9\end{array}$ & $\begin{array}{l}0.2 \\
5\end{array}$ & & \\
\hline 13. SMA & -0.03 & 0.89 & 0.05 & 0.08 & 0.06 & $\begin{array}{l}0.4 \\
1\end{array}$ & $\begin{array}{l}0.5 \\
1\end{array}$ & $\begin{array}{l}0.5 \\
6\end{array}$ & $\begin{array}{l}0.4 \\
2\end{array}$ & $\begin{array}{l}0.5 \\
2\end{array}$ & $\begin{array}{l}0.4 \\
2\end{array}$ & $\begin{array}{l}0.4 \\
2\end{array}$ & $\begin{array}{l}0.4 \\
0\end{array}$ & $\begin{array}{l}0.2 \\
4\end{array}$ & \\
\hline 14. GMA & 0.00 & 1.15 & $\begin{array}{l}-0.0 \\
1\end{array}$ & $\begin{array}{l}-0.0 \\
3\end{array}$ & $\begin{array}{l}-0.0 \\
3\end{array}$ & $\begin{array}{l}0.3 \\
1\end{array}$ & $\begin{array}{l}0.3 \\
7\end{array}$ & $\begin{array}{l}0.7 \\
9\end{array}$ & $\begin{array}{l}0.6 \\
0\end{array}$ & $\begin{array}{l}0.8 \\
0\end{array}$ & $\begin{array}{l}0.5 \\
1\end{array}$ & $\begin{array}{l}0.4 \\
6\end{array}$ & $\begin{array}{l}0.6 \\
0\end{array}$ & $\begin{array}{l}0.4 \\
5\end{array}$ & $\begin{array}{l}0.7 \\
0\end{array}$ \\
\hline
\end{tabular}

Note. $Q R=$ quantitative reasoning; $V=$ visualization; $R C=$ reading comprehension; $D R=$ deductive reasoning; $L K=$ lexical knowledge; $I R=$ inductive reasoning; $W F=$ word fluency.

Table 2. Observed validity coefficients

\begin{tabular}{|c|c|c|c|c|c|c|c|c|c|c|c|c|c|c|c|c|c|}
\hline department & $\mathrm{n}$ & QR & & $\mathrm{V}$ & $\mathrm{RC}$ & DR & & LK & & ID & & WF & & GMA & & SMA & \\
\hline \multirow{2}{*}{ board } & \multirow{2}{*}{102} & $47 * * *$ & 1 & $0.45 * * *$ & $/ 0.29 * /$ & $0.34 * *$ & & $0.25 * /$ & & $0.30 *$ & & 0.01 & & $0.51 * * *$ & & $0.58 * * *$ & 1 \\
\hline & & $17 * * *$ & & $0.44 * * *$ & $0.34 * *$ & $34 * *$ & & 0.19 & & $0.40 * *$ & & $0.22 *$ & & $0.57 * * *$ & & $0.59 * * *$ & \\
\hline \multirow{2}{*}{ buyers } & \multirow{2}{*}{45} & $37 *$ & 7 & $-0.13 /$ & $0.46 * * /$ & $39 * *$ & I & $0.2 /$ & & $0.02 /$ & & $0.12 /$ & & $0.4^{* *}$ & I & 0.5 & I \\
\hline & & $43 * * *$ & & 0.07 & $0.52 * * *$ & 0.28 & & $0.39 * *$ & & 0.18 & & -0.08 & & $0.5 * * *$ & & $0.6^{*}$ & \\
\hline \multirow{2}{*}{ clerks } & \multirow{2}{*}{5} & 05 / & & $0.06 /$ & $0.02 /$ & $0.01 /$ & & $0.10 * /$ & & $-0.06 /$ & & -0.01 & I & $0.04 /$ & & $0.10 * /$ & \\
\hline & & 03 & & -0.02 & 0.02 & 0.01 & & 0.06 & & -0.02 & & 0.08 & & 0.03 & & 0.01 & \\
\hline \multirow{2}{*}{ constructors } & \multirow{2}{*}{200} & $0.22 *$ & I & $0.26 * *$ & $/ 0.21 * /$ & $0.05 /$ & & $0.09 *$ & & $0.24 *$ & I & $0.24 *$ & I & $0.29 * * /$ & & $0.34^{*}$ & I \\
\hline & & $0.31 * *$ & & $0.25 * *$ & $0.32 * *$ & $0.22 *$ & & $0.25 *$ & & $0.32 * *$ & & $0.36 * *$ & & $-0.44 * * *$ & & $0.46 * * *$ & \\
\hline \multirow{2}{*}{ consultants } & & $20 /$ & & $0.06 /$ & $0.11 /$ & $-0.09 /$ & & $-0.07 /$ & & $-0.2 /$ & & -0.01 & I & 0.07 / & & $0.02 /$ & \\
\hline & & 13 & & -0.01 & 0.06 & -0.07 & & -0.02 & & -0.14 & & 0.01 & & 0.03 & & 0.01 & \\
\hline \multirow{2}{*}{$\begin{array}{l}\text { customer } \\
\text { service }\end{array}$} & \multirow{2}{*}{425} & $0.38 * *$ & I & $0.20 * *$ & / $0.26 * * /$ & $0.16^{*}$ & & $0.11 *$ & & $0.17 *$ & I & 0.05 & I & $0.36 * *$ & t & $0.38 * *$ & I \\
\hline & & $0.42 * * *$ & & $0.23 * *$ & $0.33 * *$ & $0.22 *$ & & $0.18 *$ & & $0.31 * *$ & & $0.20 * *$ & & $0.47 * * *$ & & 0.48 & \\
\hline \multirow{2}{*}{ financiers } & \multirow{2}{*}{415} & $0.13 * /$ & & $0.05 /$ & $0.04 /$ & $0.16^{*}$ & 1 & $0.10 *$ & I & $-0.02 /$ & & $0.11^{*}$ & / & 0.09 / & & $0.24 *$ & 1 \\
\hline & & 0.03 & & 0.04 & -0.01 & $0.21 * *$ & & $0.11 *$ & & 0.01 & & 0.03 & & 0.06 & & $0.23^{*}$ & \\
\hline \multirow{2}{*}{ HR } & \multirow{2}{*}{170} & $1 /$ & & $-0.14 /$ & $-0.10 /$ & $-0.12 /$ & & $-0.02 /$ & & $0.21 *$ & I & $0.16^{*}$ & I & $0.15 *$ & & 3* & 1 \\
\hline & & & & -0.07 & -0.12 & -0.08 & & -0.14 & & $0.22 *$ & & 0.2 & & $0.19 *$ & & $0.27 *$ & \\
\hline \multirow{2}{*}{ IT } & \multirow{2}{*}{253} & $* * *$ & I & 0.2 & / $0.41 * * *$ & / 0.3 & I & $0.33 * *$ & l & $0.18 *$ & l & $0.13^{*}$ & I & $0.51 * * *$ & I & 0.5 & I \\
\hline & & * & & 0.2 & 0.4 & $* *$ & & 0. & & 0. & & 0 . & & $* *$ & & & \\
\hline \multirow{4}{*}{$\begin{array}{l}\text { manufactory } \\
\text { workers } \\
\text { marketing } \\
\text { specialists }\end{array}$} & \multirow[b]{2}{*}{22} & $*$ & I & 0.1 & $0.24 * /$ & 0 . & I & 0 . & & 0. & & 0 . & / & $0.24 *$ & I & & I \\
\hline & & $* * *$ & & $7 *$ & $* *$ & * & & $5 *$ & & $*$ & & $*$ & & $* * *$ & & $* * *$ & \\
\hline & \multirow{2}{*}{215} & $34 * *$ & 7 & $0.20 *$ & / $0.42 * * *$ & / $0.22 *$ & I & $0.25 *$ & I & $0.20^{*}$ & l & $0.16^{*}$ & I & $0.46 * * *$ & I & $0.46 * * *$ & I \\
\hline & & $39 * *$ & & $0.29 * *$ & $0.41 * * *$ & & & $0.27 * *$ & & $0.24 *$ & & $0.23^{*}$ & & $0.53 * * *$ & & $0.53 * * *$ & \\
\hline \multirow{2}{*}{ QA's } & & $-0.11 /$ & & $0.40 * * /$ & $0.29 /$ & $0.08 /$ & & $-0.03 /$ & & $0.01 /$ & & 0.16 & l & -0.11 & 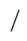 & $0.40 * *$ & I \\
\hline & & & & 0.23 & 0.09 & & & 0.18 & & & & $0.40 * *$ & & 0.33 & & $0.40 * *$ & \\
\hline \multirow{2}{*}{ researchers } & & $64 * * *$ & I & $0.50 * * *$ & / 0.18 / & $0.57 * * *$ & I & $0.31 * *$ & 1 & $0.46^{* *}$ & 1 & $0.05 /$ & & $0.68 * * *$ & I & $0.83 * * *$ & I \\
\hline & & $0.69 * * *$ & & $0.48 * *$ & $0.25 * *$ & $0.51 * * *$ & & $0.34 *$ & & & & 0.10 & & $0.70 * * *$ & & $0.79 * * *$ & \\
\hline & & $0.41 * * *$ & I & $0.25^{*}$ & $/ 0.34 * *$ & $/ 0.21 *$ & I & $0.30 * *$ & 1 & $0.15^{*}$ & 7 & $0.09 * *$ & 1 & $0.43^{* * *}$ & I & $0.46^{* * *}$ & 1 \\
\hline salespeople & & $46 * * *$ & & & & & & $0.35 * *$ & & & & & & $0.59 * * *$ & & $0.60 * * *$ & \\
\hline $\operatorname{tran}$ & & $20 *$ & 1 & 0.07 / & $0.25 * /$ & $0.22 *$ & 1 & $0.28 * *$ & / & $0.25 *$ & I & 0.10 & 1 & $0.33 * *$ & 1 & $0.39 * *$ & I \\
\hline & & & & & & & & $0.28 * *$ & & & & & & $0.42 * * *$ & & $0.43 * * *$ & \\
\hline all & & $0.31 * *$ & & $0.17 * /$ & $0.25 * * /$ & $0.18 *$ & & $0.20 *$ & & $0.10^{*}$ & T & 0.01 & 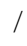 & $0.31 * *$ & & $0.40 * * *$ & \\
\hline & & $0.31 * *$ & & $0.21 *$ & $0.27 * *$ & $0.23 *$ & & $0.22 *$ & & $0.19 *$ & & $0.12 *$ & & $0.37 * * *$ & & $0.51 * * *$ & \\
\hline
\end{tabular}


Note. The first number is the coefficient for quantitative measure, the second for rating; $Q R=$ quantitative reasoning; $V$ = visualization; $R C=$ reading comprehension; $D R=$ deductive reasoning; $L K=$ lexical knowledge; $I R=$ inductive reasoning; $W F=$ word fluency.

$* \mathrm{p}<0.05 ; * * \mathrm{p}<0.01 ; * * * \mathrm{p}<0.001$.

\subsection{Hierarchical Regression Analysis}

Next, hierarchical regression models were built and compared (Table 3) and incremental validity analysis was performed. Overall, only in two cases, e.g. clerks and consulting specialists, abilities failed to significantly explained the variance in both job performance criteria. Furthermore, after building an initial model with only GMA as a predictor, and the second one with GMA and SMA composite as predictors, only in three cases (customer service, marketing and QA's) SMA did not show incremental validity (however, in the case of customer service and QA's, only when the rating of performance was being considered). In every other group, SMA proved to have significant and substantial incremental validity, which was confirmed by outcomes of ANOVA tests. On average, in the case of job performance ratings, SMA increased $R^{2}$ of the final model by $19 \%$ and by $37 \%$ in the case of job performance quantitative measure (in comparison with the initial model, with only GMA).

Table 3. Results of incremental validity analysis

\begin{tabular}{|c|c|c|c|c|c|c|c|c|c|c|}
\hline \multirow[b]{3}{*}{ department } & \multicolumn{5}{|c|}{ Dependant variable: financial outcome } & \multicolumn{5}{|c|}{ Dependant variable: rating } \\
\hline & \multirow{2}{*}{\multicolumn{4}{|c|}{$\begin{array}{l}R^{2} \text { for models: } \\
\text { GM }^{\mathrm{a}} \mathrm{SMA}^{\mathrm{a}}\end{array}$}} & \multirow[b]{2}{*}{$F^{b}$} & \multirow{2}{*}{$\begin{array}{l}R^{2} \text { for } \\
\mathrm{GMA}^{\mathrm{a}}\end{array}$} & \multicolumn{2}{|c|}{ models: } & \multirow{2}{*}{$\Delta R^{2}$} & \multirow[b]{2}{*}{$F^{\mathrm{b}}$} \\
\hline & & & & & & & $\mathrm{SMA}^{\mathrm{a}}$ & Both $^{a}$ & & \\
\hline board & 0.27 & 0.34 & 0.37 & $0.11(29 \%)$ & $16.85 * * *$ & 0.33 & 0.35 & 0.35 & $\begin{array}{l}0.02 \\
(6 \%)\end{array}$ & $2.91^{*}$ \\
\hline buyers & 0.16 & 0.27 & 0.30 & $0.15(48 \%)$ & $8.87^{* * *}$ & 0.25 & 0.36 & 0.40 & $0.15(38 \%)$ & $10.75^{* * *}$ \\
\hline clerks & 0.00 & 0.01 & 0.01 & $0.01(86 \%)$ & $5.04 *$ & 0.00 & 0.00 & 0.00 & $\begin{array}{l}0.00 \\
(0 \%)\end{array}$ & 0.14 \\
\hline constructors & 0.08 & 0.11 & 0.12 & $0.04(32 \%)$ & $8.77^{* * *}$ & 0.19 & 0.21 & 0.21 & $0.02(10 \%)$ & $5.36 * *$ \\
\hline consultants & 0.01 & 0.01 & 0.01 & $\begin{array}{l}0.00 \\
(0 \%)\end{array}$ & 0.12 & 0.01 & 0.01 & 0.01 & $\begin{array}{l}0.00 \\
(0 \%)\end{array}$ & 0.24 \\
\hline customer service & 0.13 & 0.14 & 0.16 & $0.03(20 \%)$ & $15.5^{* * * *}$ & 0.22 & 0.23 & 0.23 & $\begin{array}{l}0.01 \\
(1 \%)\end{array}$ & 1.29 \\
\hline financiers & 0.01 & 0.06 & 0.07 & $0.06(89 \%)$ & $26.57 * * *$ & 0.00 & 0.05 & 0.06 & $0.06(95 \%)$ & $26.18 * * *$ \\
\hline HR & 0.02 & 0.06 & 0.06 & $0.03(59 \%)$ & $5.72 * *$ & 0.04 & 0.07 & 0.07 & $0.04(50 \%)$ & $6.41 * *$ \\
\hline IT & 0.26 & 0.29 & 0.30 & $0.04(12 \%)$ & $12.6^{* * * *}$ & 0.39 & 0.42 & 0.43 & $\begin{array}{l}0.04 \\
(9 \%)\end{array}$ & $17.23 * * *$ \\
\hline manufactory workers & 0.06 & 0.09 & 0.12 & $0.07(54 \%)$ & $17 * *$ & 0.21 & 0.22 & 0.22 & $\begin{array}{l}0.01 \\
(7 \%)\end{array}$ & $4.12^{*}$ \\
\hline marketing specialists & 0.21 & 0.22 & 0.22 & $\begin{array}{l}0.01 \\
(2 \%)\end{array}$ & 0.92 & 0.28 & 0.28 & 0.29 & $\begin{array}{l}0.01 \\
(1 \%)\end{array}$ & 0.78 \\
\hline $\begin{array}{l}\text { QA's } \\
\text { researc }\end{array}$ & $\begin{array}{l}0.01 \\
0.46\end{array}$ & $\begin{array}{l}0.16 \\
070\end{array}$ & $\begin{array}{l}0.25 \\
0.70\end{array}$ & $\begin{array}{l}0.23(95 \%) \\
0.24(35 \%)\end{array}$ & & $\begin{array}{l}0.11 \\
0.50\end{array}$ & $\begin{array}{l}0.16 \\
0.62\end{array}$ & $\begin{array}{l}0.19 \\
0.63\end{array}$ & $0.08(41 \%)$ & $\begin{array}{l}2.89 * * \\
1242 * * *\end{array}$ \\
\hline salespeople & 0.19 & 0.21 & 0.22 & $0.03(15 \%)$ & $40.37 * * *$ & 0.35 & 0.36 & 0.36 & $\begin{array}{l}0.01 \\
(1 \%)\end{array}$ & $6.33^{* *}$ \\
\hline transition specialists & 0.11 & 0.15 & 0.15 & $0.04(27 \%)$ & $13.41 * * *$ & 0.17 & 0.19 & 0.19 & $\begin{array}{l}0.02 \\
(8 \%)\end{array}$ & $5.32 * *$ \\
\hline
\end{tabular}

Note. ${ }^{a}$ predictors included in models; ${ }^{\mathrm{b}}$ ANOVA test results for incremental validity significance.

$* \mathrm{p}<0.05 ; * \mathrm{p}<0.01 ; * * \mathrm{p}<0.001$.

Importantly, there were groups in which SMA increased the percentage of explained variance in job performance by half or more. These results oppose the aforementioned claims of a lack of incremental validity of SMA and therefore lend further support to Hypothesis 1.

\subsection{Moderation Analysis}

Along with the hierarchical regression analysis, the moderation analysis was employed. For this part, the regression models were built with only GMA as a predictor of job performance measures variance. Also, an occupational group (as a categorical variable) was included as a moderator of this relationship, along with the interaction effects of predictors. If the GMA were a universally valid job performance predictor, no interaction effect (no moderation) should be observed. An initial model (with only GMA) for the whole sample accounted for only $9 \%$ of job performance quantitative variance $(F(2,4031)=422.55 ; \quad p<0.001)$ and $14 \%$ of job performance rating $(F(2,4031)=632.73 ; p<0.001)$. When the moderator was included, the model accounted for $25 \%$ of the quantitative measure $(F(30,4003)=46.50 ; p<0.001)$ and $26 \%$ of rating $(F(30,4003)=48.01 ; p<0.001)$. Importantly, the 
interaction effects of GMA and occupational group were significant in both regression models and ANOVA tests confirmed that the models with and without interaction effects differed significantly in terms of quantitative $(F=30.03$; $d f=28 ; p<0.001)$ and rating $(F=23.58 ; d f=28 ; p<0.001)$ measures of job performance. All in all, these data support Hypothesis 2.

\subsection{Relative Importance Analysis}

In the final step, a relative importance analysis with the relative weights method was performed (Table 4). This allows a determination of the contribution that every predictor included made to the total variance of job performance, both by itself and in combination with the other predictors. More precisely, the relative weight analysis was employed (Tonidandel \& LeBreton, 2011) and the RWA-WEB was used to calculate the results (Tonidandel \& LeBreton, 2014). This method helps to determine the exact proportion of contribution that is expressed as a percentage for each predictor, which adds up to $100 \%$. The larger the percentage for a predictor, the more relatively important it is, even when other variables are taken into account (Tonidandel \& LeBreton, 2014).

Table 4. Results of relative weights analysis.

\begin{tabular}{|c|c|c|c|c|c|c|c|c|c|c|c|c|c|c|c|c|}
\hline department & QR & & V & & $\mathrm{RC}$ & & DR & & LK & & IR & & WF & & GMA & \\
\hline \multirow{2}{*}{ board } & 19.41 & I & 21.05 & I & $7.49 /$ & & 15.85 & 1 & 10.68 & I & 5.26 & I & $6.01 /$ & & 14.25 & 1 \\
\hline & 19.99 & & 18.85 & & 8.87 & & 15.67 & & 4.17 & & 13.98 & & 3.27 & & 15.19 & \\
\hline \multirow{2}{*}{ buyers } & 12.05 & I & 18.79 & I & 23.15 & I & 14.17 & I & 5.06 & I & $6.94 /$ & & $1.43 /$ & & 18.42 & I \\
\hline & 14.9 & & 2.24 & & 27.05 & & 5.92 & & 23.78 & & 1.94 & & 8.68 & & & \\
\hline \multirow{2}{*}{ constructors } & 10.1 & / & 22.82 & I & 10.62 & I & $3.64 /$ & & $1.38 /$ & & 19.57 & l & 19.2 & l & 12.66 & I \\
\hline & 10.49 & & 6.72 & & 12.92 & & 4.57 & & 9.53 & & 17.15 & & 25.64 & & 12.98 & \\
\hline \multirow{2}{*}{$\begin{array}{l}\text { customer } \\
\text { service }\end{array}$} & 40.85 & I & $8.8 /$ & & 12.88 & I & $5.05 /$ & & $2.36 /$ & & 5.82 & I & $3.57 /$ & & 20.68 & I \\
\hline & 31.17 & & 6.61 & & 13.48 & & 6.01 & & 3.68 & & 15.49 & & 4.89 & & 18.67 & \\
\hline \multirow{2}{*}{ financiers } & 17.07 & I & $1.9 /$ & & $1.71 /$ & & 26.17 & I & 14.41 & I & $3.4 /$ & & 26.84 & l & $8.51 /$ & \\
\hline & 1.47 & & 1.84 & & 2.61 & & 65.47 & & 18.59 & & 1.06 & & 2.52 & & 6.45 & \\
\hline \multirow{2}{*}{ HR } & 17.31 & I & 12.51 & l & $5.33 /$ & & $7.89 /$ & & $1.12 /$ & & 31.38 & I & 11.38 & I & 13.09 & / \\
\hline & 4.82 & & 1.94 & & 6.79 & & 2.34 & & 12 & & 34.82 & & 26.67 & & 10.62 & \\
\hline \multirow[b]{2}{*}{ IT } & 24.91 & I & $3.56 /$ & & 17.86 & I & 16.41 & I & 15.5 & / & $2.75 /$ & & $1.49 /$ & & 17.52 & I \\
\hline & 24.91 & & 3.73 & & 13.2 & & 19.41 & & 17.21 & & 5.35 & & 1.43 & & 74 & \\
\hline \multirow{4}{*}{$\begin{array}{l}\text { manufactory } \\
\text { workers } \\
\text { marketing } \\
\text { specialists }\end{array}$} & 20.69 & I & 5.52 & I & 13.16 & I & 17.79 & I & $3.01 /$ & & $3.6 /$ & & 23.44 & I & 12.8 & I \\
\hline & 2833 & & 10.48 & & 17.2 & & 14.25 & & 7.54 & & 3.89 & & 1.27 & & 17.04 & \\
\hline & 17.33 & l & $5.6 /$ & & $29.9 /$ & & 5.82 & I & 10.51 & I & $5.46 /$ & & $3.24 /$ & & 22.16 & I \\
\hline & 19.17 & & 9.95 & & 20.7 & & 12.65 & & 9.13 & & 5.08 & & 6.03 & & 17.29 & \\
\hline \multirow{2}{*}{ QA's } & $2.77 /$ & & 49.67 & l & 18.98 & I & $1.10 /$ & & $1.26 /$ & & 0.94 & I & 15.56 & l & 9.72 & I \\
\hline & 7.66 & & 8.83 & & 5.79 & & 11.91 & & 4.21 & & 10.02 & & 39.12 & & 12.47 & \\
\hline \multirow{2}{*}{ researchers } & 18.44 & I & 20.89 & l & $3.31 /$ & & 25.24 & I & $3.21 /$ & & 15.49 & I & $1.18 /$ & & 12.24 & I \\
\hline & 2776 & & 18.11 & & 5.16 & & 19.67 & & 5.11 & & 7.99 & & 0.69 & & 15.5 & \\
\hline \multirow{2}{*}{ salespeople } & 28.37 & l & 8.02 & l & 16.32 & l & $5.93 /$ & & 17.68 & / & $3.67 /$ & & $1.95 /$ & & 18.07 & I \\
\hline & 18.97 & & 12.28 & & 17.83 & & 9.17 & & & & & & & & & \\
\hline trans & $8.97 /$ & & $3.13 /$ & & 17.06 & I & 13.22 & I & 27.29 & I & 14.35 & I & $1.64 /$ & & 14.34 & I \\
\hline specialists & 15.8 & & 2.49 & & 16.38 & & 13.72 & & 19.82 & & 13.76 & & 2.93 & & 15.09 & \\
\hline
\end{tabular}

Note. All results are presented in percentages; the first number is the relative importance for quantitative measure, the second for rating; $Q R=$ quantitative reasoning; $V=$ visualization; $R C=$ reading comprehension; $D R=$ deductive reasoning; $L K=$ lexical knowledge; $I R=$ inductive reasoning; $W F=$ word fluency.

The groups where GMA and SMA significantly explain variance in job performance were taken into account at this stage. Importantly, within these 13 groups, GMA did not even once contribute to the overall variance mostly. In almost every case there were single narrow ability test results that had a superior contribution to job performance variance than GMA. On average, a single most relatively important predictor (a SMA result) contributed 108\% more in the case of the quantitative job performance measure and $140 \%$ more in the case of the rating measure than GMA did. In some cases (e.g. customer service group, financiers and HR specialists), a single SMA contributed over twice as much as GMA to the job performance measure variance. The pattern of contribution was, however, strongly diversified. There were no SMA that could be considered universally to be the most important predictor regardless of occupation. Each SMA was the predictor that contributed most to the variability of job performance in at least one group. The outcome of this analysis supports Hypothesis 1, as SMA proved to be relatively more important than GMA in predicting the variance of job performance measures.

\section{Discussion}

The SVT perspective, emphasizing the role of SMA in personnel selection, fits better the data, as results showed patterns exactly in accordance with the assumptions of this theory, i.e. the job-unique weighting composites based on 
several SMA were far superior to GMA alone in predicting job performance variance. The data presented above support both hypotheses. Drawn from Motowidlo et al. (1997) theory, one could assume SMA to be a basic tendency that leads to job performance in certain occupation, which is also relatively more important than GMA.

Schmidt (2002) noticed that GMA "has higher validity than any single aptitude" (p. 189), which is a credo of the unitarian perspective. As shown in this study, SMA had a superior validity and importance than GMA in job performance variance prediction. Furthermore, researchers who support the unitarian perspective (Carretta \& Ree, 2000; Ones, Viswesvaran, \& Dilchert, 2006; Schmidt, 2002) claimed that differences between jobs do not affect the generalizability of GMA validity. Differences in validity magnitude and importance across occupations seem to support the opposing statement. Next, when job differentiation was considered, SMA proved to have at least decent incremental validity, and importantly, adding specific weighted component to GMA in the regression model substantially increased predictive validity. Consequently, the results were contrary to the claims that SMA added little or nothing more than GMA to job performance prediction.

Overall, the validity of SMA in job performance prediction was beyond what GMA could offer. Viswesvaran \& One (2002) pointed out that SVT could not be confirmed, as GMA is responsible for most of the predicted variance in variables. The results presented support an opposite conclusion. Proponents of the unitarian perspective also claimed that SVT should be disconfirmed, as validity of SMA comes from, and is dependent on, GMA. Thanks to the methodology employed, the study results support a contrasting statement, as the relative weight analysis allows one to determine the contribution of a predictor, irrespective of its relation with other predictors (Lang et al., 2010). As the contribution of SMA was considerably larger than that of GMA, the results fit SVT better.

The results presented come from a study that does not suffer from the most pressing methodological issue that Reeve (2004) pointed out and which caused "at least the questioning of some of the evidence regarding the lack of value of narrow abilities" (p. 624). However, the results needed to be interpreted particularly carefully, as decades of studies and many meta-analytic results cannot be of course disproved by a single study. Nevertheless, in the author's opinion the data presented are robust enough to serve as proof of the concept and provoke a data-driven discussion on the actual and recent relative validity and importance of both GMA and SMA. As Krumm et al. (2014) noted, moderators and boundary conditions of the major role of GMA in performance prediction are important observations from the point of view of a validity study. This study provides data to suggest that an occupation could be such a moderator.

It is important to consider the reasons for the discrepancy between the study presented and previous findings. The dispersion of results between groups should be considered crucial, because it shows that analysis within occupations emphasizes the general differences between the predictive validity of both SMA and GMA and is essential in providing evidence for unitarian or SVT perspectives. This part of results and therefore the contribution of the study to the literature seems to be of utmost importance, as previous studies often failed to take occupational context into consideration in a systematic and comprehensive manner. Interestingly, Schneider \& Newman (2015) described the compatibility principle that could explain some of SMA predictive validity. They pointed out that GMA has better validity in the prediction of general job performance and SMA are better predictors when it comes to specific job performance. The results of this study also seem to confirm this observation, as the criterion used here seems to be strongly connected with specific job performance - the salary is often based on a series of indicators dedicated to a certain profession, and the rating of the percentage of the achieved goals relied solely on job-specific tasks.

Many meta-analytic studies did not take occupational context into consideration to a satisfactory degree and this might be the reason for the discrepancy between the results presented and the mainstream view on GMA and SMA validity. However, one could list a series of further, substantial reasons and explanations. Firstly, the meta-analyses summarized studies from decades ago (Schmidt \& Hunter, 1998). Since this study is based on recent data, it may reflect the more current state of affairs in job performance determination. Furthermore, few studies focused on the composites of SMA results specifically weighted for a given context, emphasizing instead the analysis of single scores. There is evidence that this might moderate the actual incremental validity of SMA observed in a study (Reeve, 2004; Schneider \& Newman, 2015). Finally, many validity studies were conducted on already employed participants, and therefore the range restriction of their abilities and performance was high. Thanks to the methodology employed, the results presented were free from this auto-selection issue, and might reflect outcomes closer to actual ones.

\subsection{Theoretical Implication}

Most importantly, a plausible theoretical explanation for the observed results could be identified. The validity of GMA and the superior role of SMA could be interpreted on the grounds of the triarchic theory of intelligence (Sternberg, 1997). According to the componential parts of Sternberg's theory, one could distinguish different components of information processing. The metacomponents are responsible for the management of one's mind and play executive function. They are responsible for a correct identification of a given problem and for making decision regarding the best 
way to resolve that problem (Diamond, 2013; Sternberg, 1985). The performance components are in turn the processes that are directly used to solve a given problem; they carry out the action that metacomponents command (Sternberg, 1997). On this basis, one can assume that GMA play the role of metacomponents, used in identifying a job problem and deciding on how to perform, while SMA serve as performance components and are actually used to handle job tasks easily and faultlessly. That is why in the majority of cases a moderate level of GMA is required to perform at a minimum level. This process explained also the high importance and incremental validity of SMA, as performance components have a complementary role over metacomponents.

\subsection{Practical Implication}

Results from the study presented can be used by HR practitioners in competency modeling processes and could support decisions concerning the selection tools chosen by companies. Information about the validity of SMA and GMA could be used both as grounds for new competency models based on abilities and for the development of current models used in organizations. Organizations should be interested in basing decisions about HR processes on empirical evidence, because, as the study has demonstrated, they may be able to carry out successful personnel selection using a limited range of tools (a few tests, instead of a whole battery) with comparable results (but saving time and resources).

\subsection{Limitation and Further Guidelines}

There are of course some limitations to this research that should be noted. Measurements of performance in this study gave rise to concerns. Such measures as salary and self-reports are vulnerable to many cofounders. Both of the measures used have problems with content validity. On the other hand, the use of quantitative criteria is one of the most contributing parts of this study. As Rojon et al. (2015) noted, many authors avoid them as they often result in lower coefficients. Furthermore, the two measures of construct in interest were employed, according to the criterion-driven approach, which also should contribute to reliable results (Kaplan, Cortina, \& Ruark, 2010). Nevertheless, the measures are debatable, at best. This, of course, limits the possibility to generalize conclusions drawn from the results to certain criteria and reduces to some degree the comparability of this study. It is, however, worth noting that the intention of the author was to provide proof of the concept and to deliver data to identify a relative validity of GMA and SMA. It seems reasonable that the employed measures could be regarded sufficient for those purposes.

One could list a series of guidelines that need to be followed in validation studies if they are to provide useful data. As analyzing predictive validity with or without occupational grouping has a major impact on the results, the coefficients should always be presented for certain groups (the more specific, the better). Future validation research should focus on a systematic comparison of the predictive validity of GMA and SMA across a series of occupations, with the use of a series of job performance criteria. At this point, studies investigating single predictors for one occupational group seem to have very limited utility. Overall, this will allow researchers to conduct more detailed systematic review studies and compare the relative importance of predictors.

\section{Conclusion}

There is a reasonable basis to have a further debate on SVT in personnel selection and it is no wonder that this perspective has been gaining importance in recent years (Lang et al., 2010; Reeve, 2004; Schneider \& Newman, 2015; Stanhope \& Surface, 2014). It is worth referring to Schmidt's significant statement (2002) that "there cannot be a serious debate" (p. 188) whether GMA is the best performance predictor. No one questions the valid role of GMA as a job performance predictor, but there certainly should be a debate.

\section{References}

Barros, E., Kausel, E. E., Cuadra, F., \& Díaz, D. A. (2014). Using General Mental Ability and Personality Traits to Predict Job Performance in Three Chilean Organizations. International Journal of Selection and Assessment, 22(4), 432-438.

Bertua, C., Anderson, N., \& Salgado, J. F. (2005). The predictive validity of cognitive ability tests: A UK meta-analysis. Journal of Occupational and Organizational Psychology, 78(3), 387-409. https://doi.org/10.1348/096317905X26994

Carretta, T. R., \& Ree, M. (2000). General and specific cognitive and psychomotor abilities in personnel selection: The prediction of training and job performance. International Journal of Selection and Assessment, 8(4), 227-236. https://doi.org/Doi 10.1111/1468-2389.00152

Carretta, T. R., \& Ree, M. J. (1997). Expanding the Nexus of Cognitive and Psychomotor Abilities. International Journal of Selection and Assessment, 5(3), 149-158. https://doi.org/10.1111/1468-2389.00055

Cote, S., \& Miners, C. T. H. (2006). Emotional Intelligence, Cognitive Intelligence, and Job Performance. Administrative Science Quarterly, 51(1), 1-28. 
Diamond, A. (2013). Executive Functions. Annual Review of Psychology, 64(1), 135-168. https://doi.org/10.1146/annurev-psych-113011-143750

Downey, L. A., Lee, B., \& Stough, C. (2011). Recruitment Consultant Revenue: Relationships with IQ, personality, and emotional intelligence. International Journal of Selection and Assessment, 19(3), 280-286. https://doi.org/10.1111/j.1468-2389.2011.00557.x

Hausdorf, P. A., \& Risavy, S. D. (2015). Predicting training and job performance for transit operators. International Journal of Selection and Assessment, 23(2), 1-5. https://doi.org/10.1111/ijsa.12107

Hirsh, H. R., Northrop, L. C., \& Schmidt, F. L. (1986). Validity generalization results for law enforcement occupations. Personnel Psychology, 39(2), 399-420. https://doi.org/10.1111/j.1744-6570.1986.tb00589.x

Hogan, J., Hogan, R., \& Gregory, S. (1992). Validation of a sales representative selection inventory. Journal of Business and Psychology, 7(2), 161-171. https://doi.org/10.1007/BF01013926

Hunter, J. E., \& Hunter, R. F. (1984). Validity and utility of alternative predictors of job performance. Psychological Bulletin, 96(1), 72-98. https://doi.org/10.1037/0033-2909.96.1.72

Johnson, J. W., \& Lebreton, J. M. (2004). History and Use of Relative Importance Indices in Organizational Research. Organizational Research Methods, 7(3), 238-257. https://doi.org/10.1177/1094428104266510

Kaplan, S., Cortina, J., \& Ruark, G. A. (2010). Oops.... We Did It Again: Industrial-Organizational's Focus on Emotional Intelligence Instead of on Its Relationships to Work Outcomes. Industrial and Organizational Psychology, 3(02), 171-177. https://doi.org/10.1111/j.1754-9434.2010.01220.x

Krumm, S., Schmidt, A. L., \& Lipnevich, A. A. (2014). Specific Cognitive Abilities at Work. Journal of Personnel Psychology, 13(3), 117-122. https://doi.org/10.1027/1866-5888/a000117

La Grange, L., \& Roodt, G. (2007). Personality and cognitive ability as predictors of the job performance of insurance sales people. SA Journal of Industrial Psychology, 27(3), 35-43.

Lakens, D., Hilgard, J., \& Staaks, J. (2016). On the reproducibility of meta-analyses: six practical recommendations. BMC Psychology, 4(1), 24. https://doi.org/10.1186/s40359-016-0126-3

Lang, J. W. B., Kersting, M., Hülsheger, U. R., \& Lang, J. (2010). General mental ability, narrower cognitive abilities, and job performance: The perspective of the nested-factors model of cognitive abilities. Personnel Psychology, 63(3), 595-640. https://doi.org/10.1111/j.1744-6570.2010.01182.x

LeBreton, J. M., Scherer, K. T., \& James, L. R. (2014). Corrections for Criterion Reliability in Validity Generalization: A False Prophet in a Land of Suspended Judgment. Industrial and Organizational Psychology, 7(4), 478-500. https://doi.org/10.1111/iops.12184

Marcus, B., Goffin, R. D., Johnston, N. G., \& Rothstein, M. G. (2007). Personality and Cognitive Ability as Predictors of Typical and Maximum Managerial Performance. Human Performance, 20(3), 275-285. https://doi.org/10.1080/08959280701333362

Motowidlo, S. J., Borman, W. C., \& Schmit, M. J. (1997). A Theory of Individual Differences in Task and Contextual Performance. Human Performance, 10(2), 71-83. https://doi.org/10.1207/s15327043hup1002_1

Mount, M. K., Oh, I. S., \& Burns, M. (2008). Incremental validity of perceptual speed and accuracy over general mental ability. Personnel Psychology, 61, 113-139. https://doi.org/10.1111/j.1744-6570.2008.00107.x

Muchinsky, P. M. (1993). Validation of Intelligence and Mechanical Aptitude Tests in Selecting Employees for Manufacturing Jobs. Journal of Business and Psychology, 7(4), 373-382.

Olea, M., \& Ree, M. J. (1994). Predicting pilot and navigator criteria: Not much more than g. Journal of Applied Psychology, 79(6), 845-851. https://doi.org/10.1037/0021-9010.79.6.845

Ones, D. S., Viswesvaran, C., \& Dilchert, S. (2006). Cognitive ability in selection decisions. In D. Wilheml \& R. Engle (Eds.), Understanding and measuring intelligence. London: Sage Publications.

Ree, M. J., \& Earles, J. A. (1992). Intelligence Is the Best Predictor of Job Performance. Current Directions in Psychological Science, 1(3), 86-89. https://doi.org/10.1111/1467-8721.ep10768746

Ree, M. J., Earles, J. A., \& Teachout, M. S. (1994). Predicting Job Performance: Not Much More Than g. Journal of Applied Psychology, 79(4), 518-524.

Reeve, C. L. (2004). Differential ability antecedents of general and specific dimensions of declarative knowledge: More than g. Intelligence, 32(6), 621-652. https://doi.org/10.1016/j.intell.2004.07.006 
Richardson, K., \& Norgate, S. H. (2015). Does IQ Really Predict Job Performance? Applied Developmental Science, 8691(February), 1-17. https://doi.org/10.1080/10888691.2014.983635

Rojon, C., McDowall, A., \& Saunders, M. N. K. (2015). The Relationships Between Traditional Selection Assessments and Workplace Performance Criteria Specificity: A Comparative Meta-Analysis. Human Performance, 28(1), 1-25. https://doi.org/10.1080/08959285.2014.974757

Salgado, J. F., Anderson, N., Moscoso, S., Bertua, C., de Fruyt, F., \& Rolland, J. P. (2003). A meta-analytic study of general mental ability validity for different occupations in the European community. The Journal of Applied Psychology, 88(6), 1068-1081. https://doi.org/10.1037/0021-9010.88.6.1068

Schmidt, F. L. (2002). The role of general cognitive ability and job performance: Why there cannot be a debate. Human Performance, 15(1/2), 187-210.

Schmidt, F. L., \& Hunter, J. E. (1998). The validity and utility of selection methods in personnel psychology: Practical and theoretical implications of 85 years of research findings. Psychological Bulletin, 124(2), 262-274. https://doi.org/10.1037/0033-2909.124.2.262

Schneider, W. J., \& Newman, D. A. (2015). Intelligence is multidimensional: Theoretical review and implications of specific cognitive abilities. Human Resource Management Review, 25(1), 12-27. https://doi.org/10.1016/j.hrmr.2014.09.004

Stanhope, D. S., \& Surface, E. A. (2014). Examining the incremental validity and relative importance of specific cognitive abilities in a training context. Journal of Personnel Psychology, 13(3), 146-156. https://doi.org/10.1027/1866-5888/a000116

Sternberg, R. J. (1985). Beyond IQ: A Triarchic Theory of Intelligence. Cambridge: Cambridge University Press.

Sternberg, R. J. (1997). A Triarchic View of Giftedness: Theory and Practice. In N. Coleangelo \& G. A. Davis (Eds.), Handbook of Gifted Education (pp. 43-53). Boston, MA: Allyn and Bacon.

Sternberg, R. J. (2001). The relationship between academic and practical intelligence: a case study in Kenya. Intelligence, 29(5), 401-418. https://doi.org/10.1016/S0160-2896(01)00065-4

Thomas, J. C., Barrett, G. V., \& Alexander, R. A. (1996). The relationship of specific mental ability measures compared to a general mental ability measure to quality and quantity performance on a clerical job sample. Journal of Business and Psychology, 11(1), 35-41. https://doi.org/10.1007/BF02278253

Tonidandel, S., \& LeBreton, J. M. (2011). Relative Importance Analysis: A Useful Supplement to Regression Analysis. Journal of Business and Psychology, 26(1), 1-9. https://doi.org/10.1007/s10869-010-9204-3

Tonidandel, S., \& LeBreton, J. M. (2014). RWA Web: A Free, Comprehensive, Web-Based, and User-Friendly Tool for Relative Weight Analyses. Journal of Business and Psychology, 1-10. https://doi.org/10.1007/s10869-014-9351-z

Verbeke, W. J., Belschak, F. D., Bakker, A. B., \& Dietz, B. (2008). When Intelligence Is (Dys)Functional for Achieving Sales Performance. Journal of Marketing, 72(4), 44-57. https://doi.org/10.1509/jmkg.72.4.44

Vinchur, A. J., Schippmann, J. S., Switzer, F. S., \& Roth, P. L. (1998). A Meta-Analytic Review of Predictors of Job Performance for Salespeople. Journal of Applied Psychology, 83(4), 586-597. https://doi.org/10.1037/0021-9010.83.4.586

Viswesvaran, C., \& Ones, D. S. (2002). Agreements and Disagreements on the Role of General Mental Ability (GMA) in Industrial, Work, and Organizational Psychology. Human Performance, 15(1), 211-231. https://doi.org/10.1207/S15327043HUP1501\&02_13

Whetzel, D. L., McCloy, R. A., Hooper, A., Russell, T. L., Waters, S. D., Campbell, W. J., \& Ramos, R. A. (2011). Meta-Analysis of Clerical Performance Predictors: Still stable after all these years. International Journal of Selection and Assessment, 19(1), 41-50. https://doi.org/10.1111/j.1468-2389.2010.00533.x

\section{Copyrights}

Copyright for this article is retained by the author(s), with first publication rights granted to the journal.

This is an open-access article distributed under the terms and conditions of the Creative Commons Attribution license which permits unrestricted use, distribution, and reproduction in any medium, provided the original work is properly cited. 